organism is sufficient to arrest or nullify its activities and to lead to its disappearance.

I wish to put before you a somewhat more definite view as to how iodoform inunctions aut in curing tuberculous peritonitis. When iodide of potassium is given by tbe stomach in a short time the presence of iodide can be detected in the saliva and in the urine. So when iodoform is rubbed into the skin of the abdomen in a young person it probably rapidly enters the blood and is, if regularly applied, continuously eliminated in the secretions, including the secretions into the serous cavities, and as these do not pass out of the body as the secretion of the kidneys does, they must, in course of time, become pretty richly charged with iodine compounds, at any rate sufficiently so to act as antitoxin to the tubercle toxin or as anti-bacterial to the bacilli. The first thing to be determined was whether the iodoform in the ointment. when rubbed into the abdominal surface, was absorbed into the blood quickly and eliminated by the secreting organs such as the kidneys. Dr. Still has been so good as to make this observation for me at the Children's Hospital in Great Ormond-street. He found first, that iodoform ointment is excreted and easily recognisable in the urine as iodine or the salts of iodine; and, secondly, that the rate of excretion is very rapid. When half a drachm was applied to the abdomen it was recognisable in the urine four hours later, and apparently, after a second application, it reappeared in the urine in two hours' time. When only 15 grains were applied in another case it was recognisable in the urine $15 \frac{1}{2}$ hours after application. We have proof here of the rapidity with which iodoform is absorbed by the skin, enters the blood, and circulates as an iodine compound through the tissues of the body and is eliminated into the secretions.

Now, it is an interesting circumstance in this connexion that the idea that iodine is an antitoxin to tubercle bas long been in the minds of physicians. I use the word "antitoxin" in a wide and general sense. I quoted in the beginning of this lecture Sir Thomas Watson's gloomy prognosis in cases of tuberculous peritonitis. I will now quote what he adds: "It has been thought that friction upon the abdomen with ointments containing iodine have done good, so that it will be well to make trial of such." Quite recently ${ }^{8}$ two Italian physicians have recorded a case of tuberculous peritonitis in which a cure quickly followed the injection of a solution of iodine made by dissolving 15 grains of iodine and 30 grains of iodide of potassium in one and a half ounces of water. They injected first half a syringeful and then a syringeful in the genital region daily for 10 days and then on alternate days. After about a fortnight some of the fluid was withdrawn from the peritoneal cavity and examined bacteriologically, culture preparations were made, and guineapigs were experimented on, but no tubercle was found. After 10 weeks of treatment the patient was discharged cured.

While thinking over these cases $I$ called to mind having read of a Swedish physician, Dr. Emil Nilsson, who reported that he had cured one undonbted case of taberculons meningitis by rubbing into the shaved scalp an ointment of iodoform ( 1 in 10), and $I$ found the following amongst my notes. The patient was a boy, eight years old, four of whose brothers and sisters had died from tuberculous meningitis and whose mother's family were phthisical. The symptoms were headache, torpor, convulsions, strabismus, and pyrexia. After other ineffectual treatment, the child becoming steadily worse, the head was shaved and iodoform ointment was rubbed in and an oilskin cap was put on. This was done three or four times a day. Improvement soon followed this treatment and consciousness was restored. There were, however, severe coryza, redness of the lips, and an irritable cough, the breath smelling strongly of iodoform. The ointment was discontinued and syrup of the iodide of iron was given. The unpleasant symptoms rapidly disappeared and the child was soon running about in good health.

In The LANCET of Jan. 16th, 1897, p. 159, there appeared a paper by Professor Thoma of Geneva advocating the treatment of tuberculous peritonitis by creasote given in enemata. He gave at first five minims, increased afterwards to 15 minims, in four ounces of emulsified cod-liver oil, once daily. He continued this for some weeks and then interrupted the treatment for five or six days. He obtained good results. He remarks that "laparotomy is no doubt the best and quickest of all methods for dealing with these cases

8 Brit. Med. Jour., Epitome, Sept. 9th, 1899 in which the peritoneum is covered with miliary tubercles, but," he very sensibly adds: "It is always a serious operation and one also which not every practitioner is competent to perform, and moreover parents often object, and physicians would gladly welcome other methods." The method which I followed in the three cases $I$ have related to you of the outward application of iodoform ointment and the internal administration, three times a day, of small doses of iodoform and creasote, is, I think, more promising than surgical operations in those cases in which there is evidence of intestinal ulceration. The disease is thus attacked on both sides-the peritoneal and the intestinal-by antibacterial agents.

In conclusion, I would suggest that we should bear in mind that " antitoxins" are not limited to animal products and that we should not neglect the study of those which may be found in the mineral and vegetable world. We must not be led away by fashion and popularity to neglect every kind of remedial agent that is not a "serum" or an animal extract. The oldest and surest antitoxins we possess are mercury and quinine-one from the mineral, the other from the vegetable world. Their effects are better known, are more certain, and are more reliable than those of any other antitoxin at present known to us. That many animal extracts and animal fluids should possess active therapeutic properties, as many vegetable extracts do, was only to be expected. Let us by all means study their effects and learn the extent and the limitations of their uses; but do not let us neglect the study of other curative agents or consider them less important and less interesting because they are not derived from animal sources.

\section{SOME PERSONAL EXPERIENCES OF THE EPIDEMIC OF ENTERIC FEVER AMONG THE TROOPS IN SOUTH AFRICA, IN THE ORANGE RIVER COLONY. ${ }^{1}$}

By H. H. TOOTH, M.D. CantaB., F.R.C.P. Lond.

IT has been my privilege to be actively engaged in one of the most extensive and serious epidemics of enteric fever of modern times. Any value that the following recollections and reflections may possess must be attributed rather to their being the outcome of personal observation on the spot than to any particular qualification on the part of the observer other than may be claimed by a general hospital physician. I must thank the council of the Clinical Society of London most heartily for having done me the bonour to ask me to open this discussion.

I wish to speak about myself as little as possible, but I cannot refrain from taking this opportnnity of recording the extreme cordiality and courtesy with which I was received wherever I was sent by all ranks of the Royal Army Medical Corps, from the Surgeon-General downwards, and I cannot but believe that the intercourse, social and professional, that was established between the military and civil branches of our prcfession in the ups and downs of the great campaign may help to lessen the distance which has insensibly grown between them, to the detriment of the service on the one hand and to our loss on the other.

I propose to limit my remarks this evening to a discussion of the outbreak of enteric fever on the Orange River Colony side of the campaign, from the following points of view : (1) the origin of the epidemic ; (2) the dissemination of the disease; (3) the general precautions taken to limit the spread of the disease; (4) preventive inoculation; and (5) some remarks on treatment in hospital.

THE ORIGIN OF THE EPIDEMIC.

It is, as may be expected, very difficult to assign a definite date for the first appearance of this insidious disease. But it was in the Modder river camp that we must look for the first cases, and I was given every facility by the colonel and officers of the Guards' Brigade Field Hospital, with whom I

1 Being the opening paper of a discussion upon the Recent Fpidemic of Typhoid Fever among the Troops in South Africa, read before the Clinical Society of Loudon on March $8 \mathrm{th}, 1901$. 
was staying in February, 1900, for obtaining information on this point, and though unfortunately I did not compare the facts so obtained with the experience of the other fiold hospitals, yet I think that we may take the experience of the Guards as being probably typical of that of the whole force. From the admission and discharge book of the Guards' Hospital we find that enteric fever made its first appearance about Dec. 23rd. Four men of the same company, known to be friends, reported sick at about the same time and therefore they may be assumed to have been infected at somewhere about the same date. $U_{\rho}$ to this time dysentery was the predominant feature of the daily record of admissions, but after this date enteric fever almost replaced it. It must be remembered that the Guards arrived in South Africa in the latter part of November, 1899 , and they proceeded after disembarkation straight up to Orange river station, where they halted for two or three days. The battle of Belmont was fought on Nov. 23rd, that of Enslin on the 25th, that of Modder river on the $28 \mathrm{th}$, and that of Magersfontein on Dec. 11th. The Guards were in all these engagements. The long wait of the troops at the Modder began on Dec. 12 th.

Now, of course, the date of infection of the first cases of enteric fever above alluded to must be entirely a matter of speculation. But putting the incubation period at the outside at three weeks we are forced to the conclusion that the enteric infection took place in the vicinity of Modder river. That the disease could have been imported from Fngland or even from the Cape seems highly improbable. Modder river cannot be said to be a town or even a village. It consists of the station, a small hotel which was the headquarters of the staff, a store, and a schoolhouse, all near the station. There were several small farmhouses and two or three little hotels, mostly on the banks of the two rivers. The Modder and the Riet rivers join to form one river which retains the name of the Riet, and near this junction the railway crosses the Riet by a fine viaduct which was wrecked by the Boers. The two rivers are picturesque, with well-wooded banks, and serve in times of peace as a pleasure resort for the people of Kimberley.

Kimberley is regularly visited by enteric fever and it is therefore possible that the soil about Modder river station may nave become contaminated. Jacobsdal is on the Riet about 10 miles above the camp, and it was known that there were cases of enteric fever there. There is therefore every possibility that men might have been infected by drinking the water of the Riet; but the main source of watersupply was the Modder, and there was no known contamina. tion of it at this time in its course above.

As we shall see later, though it is impossible to acquit the water-supply of having a share in the origin, yet in all probability other agencies played a still more important rôle in the spread of the disease. It is important to bear in mind that this outbreak at Modder river was probably the direct antecedent cause of the great epidemic at Bloem. fontein, and that the troops who entered Bloemfontein were deeply tainted with the disease.

The principal medical officer, Colonel Townsend, kindly allowed me to see the daily returns of enteric fever cases from Jan. 29 th to Feb. $6 \mathrm{th}, 1900$, and though I think that they understate the true state of the case, yet they give some idea of the rate at which the disease progressed in the early days. Up to Jan. 29 ih 97 cases had been reported and 17 deaths. On Feb. 6th the total had reached 156 cases and 27 deatbs. These figures seem small, but they are fairly evenly distributed over the whole camp, indicating a widespread incidence. The general advance began about Feb. 11th, Kimberley being relieved on the 15th. Jacobsdal was occupied on Feb. 16th, and the next day Paardeberg was surrounded. 10 days were spent around Paardeberg which surrendered on the $27 \mathrm{gh}$. Bloemfontein was occupied on March 13th, ahout a month after the move from Modder river. The possibilities of infection on this long march, especially during the investment of Cronje's laager, must have been very considerable, but the fact of the widespread infection of the forces at Modder river must not be lost sight of, and there can be no doubt that men were falling out sick with the disease every day from the first day of the advance. The Bloemfontein epidemic should be regarded as the direct continuation of that begun at Modder river.

Dissemination of the Disgase.

An army consists largely of individuals of the age most vulnerable to enteric infection. It would be impossible to find a more suitable medium for the growth and dissemination of the bacilli than an army of 40,000 young men of ages between 19 and 25 years. Given therefore a preliminary case or two and from quite small beginnings indefinitely large and serious results may follow. We will now discuss at some length the various agencies by means of which this scourge may be spread over a camp, or by communication by man to man.

Water.-Here, as in Fngland, the water-supply deserves our first attention. The water-supply of the camp at Modder river station included the Modder, the Riet, and certain wells. The river water was charged with thick yellow mud, which was so fine that it seemed never to settle and which rapidly clogged any filter. As will be explained further, the authorities used various means for purifying the water and even caused wells to be sunk, but all these efforts were rendered futile by the action of the soldiers themselves who appeared to prefer the untreated river water. One never passed the drift without seeing the men drinking from the river and filling their bottles. If, therefore, there was any enteric contamination of either of the rivers above, the water-supply must be held to have had a considerable share in the propagation of the disease. The soldiers were also bathing all day in the Modder, but below the point at which the water was drawn for drinking purposes. No doubt many men with the disease on them would be bathing at times and might thus infect their comrades. There was a well at the Station Hotel from which the Headquarter staff was supplied. This water looked clear and sparkling, but the chemical examination of it was less favourable than even of that of the Modder river itself,

At Bloemfontein the question of water-supply was a very pressing one and on my arrival there I was asked to serve on a board to inquire into the water-supply and drainage of the camps. It will be remembered that the waterworks at this time were in the hands of the enemy, so we had to rely entirely upon local sources of supply. These consisted of wells and the spring from which the city takes its name. The spring is situated to the south-west of, and close to, the town. It consists of a brick-lined reservoir of about 10 feet square covered in by a small red brick building, evidently an old engine-house. This all lies in a dip in the ground, and is inclosed by a paling. The veldt on this side of the city drains into two large natural ditches or dongas which receive in their course numbers of smaller ones. These two dongas meet not far from the spring to form one large watercourse which runs through the town. In ordinary circumstances this is dry, but in the rains it and its tributary dongas become rushing torrents, as we had ample opportunity of seeing for ourselves. On the banks of these dongas were several camps; for instance. not 400 yards away was a field hospital in which were 60 enteric ferer cases and provided with open trench latrines. Moreover, a donga is a convenient dumping ground for all sorts of refuse. There was no evidence or suspicion that there was any communication between the spring and the donga which were at least 30 yards apart, but the field hospital above alluded to was ordered to be removed. Another action of this board was to cause the provision of bucket latrines to all hospitals and other camps; this was a very important and salutary measure. The water of the spring looked good, but by chemical analysis I found that it contained a suspiciously high percentage of absorbed oxygen and a trace of nitrites. In addition to the spring the city and forces had to rely on wells of which there were several. I have personal knowledge, however, only of those near our own camp, and these were of the tube variety sunk through over 100 feet of underlying rock. These wells gave a good supply of excellent water and from the manner of their construction they were free from any possibility of surface contamination. There were two of them at first and the engineers soon sank another. But these were not sufficient for the needs of the whole camp and so the spring continued to be used as well.

The water-supply from the Modder reservoir was re-opened in May when the epidemic was moderating and therefore can scarcely be looked upon as a factor of influence in itself either way. However, I made several chemical examinations of this water and found it very unsatisfactory, containing a large percentage of absorbed oxygen. Thinking that it might be contaminated in its coure throngh the mains, especially after a long period of stagnation, I procured water direct from the reservoir and found it still far 
from satisfactory. It. is, however, quite probable that the contamination was of a harmless vegetable nature. All these chemical analyses are open to the objection that they give no hint as to the real nature of the organic material. They should be regarded as danger signals only; a personal examination of the source and course of transmission is of much more value, but unfortunately it is often impossible. It is quite obvious that a harmless water may give a very unsatisfactory analysis, while an apparently pure sample may contain many bacilli. Bacterial examinations can scarcely be expected under the circumstances, even if they were of much value.

The results of atmospheric disturbances. $-\mathrm{A}$ visitor to the camp at Modder river would not have to wait long to see a sandstorm, and one would be quite enough to satisfy any curiosity which he might have had. The veldt, generally speaking, is a plain of sand in so fine a state of division as to deserve the name of dust. After the rains there is a certain amount of loose vegetation which binds the sand, and rain and sun also harden the surface which is not, under ordinary circumstances, much affected by the wind; but by the incessant movement of horses, men, and vehicles the surface becomes so ploughed up that one might walk a mile or more ankle deep in soft reddish-yellow dust. From time to time a gale would spring ap, and in a short time the whole camp would, on the brightest day, be buried in the darkness of a London fog, and sand and dust would cover everything and everybody. On still days even it was rare not to be visited by a number of small whirlwinds, called "sand-devils," which would pass slowly along sucking up quantities of sand and any light articles such as pieces of paper, carrying them to an astonishing height in the air and depositing them broadcast. The result of all this was that sand entered largely into every article of food, for the cooking was performed in the open air. The air at that time was intensely dry, so that it is not too much to suppose that all sorts of fæcal and urinary contamination must have been disseminated with the sand and dust. The same state of things obtained at Bloemfontein but in a minor degree, because the atmospheric conditions were generally quieter at that time of the year.

As a factor, then, in the spread of enteric fever we must by no means overlook sandstorms, which are everyday phenomena in many parts of the world where the British army may be sent, and it is quite a question whether they have not been more important factors in this war than the water itself. For that the water contained enteric fever bacilli is a matter of speculation, but that enteric stools and urine must have been deposited in the latrines and other places by men in the early stages of the disease there can be no reasonable doubt.

slies. - As may be expected the conditions in these large camps were particularly favourable to the growth and multiplication of flies which soon became a terrible pest. I was told by a resident at Bloemfontein that these insects were by no means a serious plague in ordinary times, but that they came with the army. It would be more correct to say that the normal number of flies was increased owing to the large quantities of refuse, dead borses, \&c., upon which they could feed and multiply. They naturally infest persons who are ill but seem to be peculiarly attracted to enteric fever patients, hanging in loathsome groups around their mouths and feeding-vessels. They were all over our food and the roofs of our tents were at times black with them. It is not unreasonable to look upon flies as a very possible agency in spreading the disease not only abroad but at home. Most of the temperature charts that had hung over the patients' beds were plentifully spotted with the excreta of flies and on my return home Dr. Schölberg was so kind as to make cultivations from them; but though he obtained cultures of many organisms he did not isolate the enteric fever bacillus, which circumstance, however, as he says, is not a matter for surprise considering the age of the material (three months at least).

It is a well-known fact that with the first appearance of the frost enteric fever almost rapidly disappears. The winter in South Africa is very mild compared with that which we are accustomed to in England. It is true that the nights are cold, sometimes to many degrees of frost. But the days are warm and bright; for instance, in my tent at midday the temperature was rarely below $70^{\circ} \mathrm{F}$. and sometimes as high as $80^{\circ}$-in fact, about the temperature of an English summer day. It seems hardly credible that the almost sudden cessation of an epidemic can be due to the effect of cold upon the enteric fever bacilli only. But there can be no doubt in the mind of anybody who has been living on the open veldt as we have for three or four months that the flies are extremely sensitive to the change of temperature and that the cold nights kill them off rapidly. On consideration of these points it is surely justifiable to assign an important share to fies in the spreading of infection.

Personal infection from man to man.-Even in the best ordered London hospital it is unfortunately not uncommon to see enteric fever pass from patient to nurse and so to other patients. On consideration of the mode of life of the soldier. on active service one is struck by the facilities which it offers for infection. Personal cleanliness is often an impossibility even for officers, much less for privates. There is barely enough water for drinking, let alone for washing purposes. The men slept 15 in a tent-when there were tents-and that fact presented considerable possibilities for infection. Far be it from me to say that the soldier is naturally dirty, but there can be no doubt that he bas no idea of hygienic matters. This is shown forcibly by our experience at Bloemfontein. We had a large number of officers down with enteric fever, and as the nursing was at that time very heavy we were glad to avail ourselves of the help of the personal servants of these officers. They had not much to do, of course, with the direct nursing of their masters, but nevertheless a large number of them contracted the disease while with us. Of course some of them may have been infected at the same time as their masters. On the otber hand, of our own orderlies, eight only took the disease in the whole seven months, though they were in constant attendance on bad cases. This may be due to protective inoculation, but it is also probably owing to their being alive to the ordinary precautions necessary. Bearing in mind the insidious mode of onset of enteric fever it is obvious that at any one time there must have been in these large camps, many men still at duty, with the disease on them, and therefore capable of giving it to their comrades in the close intercourse of camp life.

In conclusion of this part of $m y$ subject $I$ cannot belp remarking that, far from its being a matter of surprise that the epidemic was so severe, it seems to me, who have lived through it, a matter of congratulation that it was not more so, considering how many unavoidable causes were at work.

The probable effects of diseases antecedent to infection.Here seems to be the place to discuss shortly certain points of more than academic interest, but for which clinical data are at present, so far as I know, lacking. It is known, experimentally, that the virulence of the bacillus becomes mush increased by the presence in the blood of the toxins of other organisms, even of such as are found normally in the alimentary canal-as bacillus coli, for instance. ${ }^{2}$ That is to say, an injection of a culture of enteric fever bacilli of slight, non-letbal virulence, may become greatly increased in virulence after the intra-peritoveal injection of streptococcus toxin. I quote from Dr. Horton-Smith's lecture ${ }^{3}$ : "Sanarelli showed ...... that all that is necessary is to inject into a guinea-pig at first a dose not quite sufficient to be fatal. The animal recovers, but for some time afterwards attenuated typhoid bacilli may be found in the purulent focus at the seat of inoculation. If now, in this condition a dose of toxins either of bacillos coli or of bacillus protens vulgaris be injected into the peritoneum the typhoid bacilli at once acquire fresh virulence, the organism is invaded afresh, and the animal dies from acute experimental typhoid fever. More important still, on two occasions be was able to determine such a relapse by injecting small quantities of the toxin in to the stomach and so into the intestines, thus exactly reproducing the conditions occurring in the human'subject." Here we have an important principle enunciated from the laboratory, but which opens up a field of speculation per haps not altogether profitless. It is conceivable, nay, more than probable, that every man in these great camps. ourselves among the number, may have at times received into the alimentary canal enteric fever bacilli which may have grown and multiplied but without producing the characteristic disease. If this be so we may assume the existence of an immunity such as a previous attack might establisb, or, as it is hoped, inoculation may imitate, or a natural immunity that we wonder at but cannot explain. It may be

2 Horton-Smit.b : Goulstonian Lectures, 1900, in $\mathrm{x}$ hich this question is fully discussed, with manv references. 
that \&uch bacilli never get through into the circulation, but are passed away harmless. It is almost allowable to go a step further in speculation and to admit the possibility of the bacilli actually circulating in the blood without causing the disease. This is not so chimerical an idea as may appear at first sight, for it is now well known that persons who have had the disease may retain bacilli in their tissues for indefinite periods, years even, without harm to themselves.

But suppose, in the light of laboratory experience, some other toxin to come on the scene, then the bacilli acquire a new virulence and the disease may assert itself. Such a startingpoint might be supplied by a simple attack of gastro-enteritis with the multiplication of bacilli normally existing in the intestines in small numbers. I need scarcely enlarge upon the possibilities of such a trouble among soldiers with bad teeth and improper food. The enteric fever epidemic has so overshadowed, in the public mind, all other medical ailments that we are apt to overlook the fact that dysentery or its milder forms included under the head of diarrhoea was quite as prevalent among the troops as enteric fever was. It would be quite difficult to find a man who had not had diarrhcea for some time, longer or shorter, during his stay in South Africa. We were struck by the fact that in many of our cases the onset of the enteric fever appeared in the course of dysentery. I strongly suspect that the two diseases may exist in the same patient and that such a conjunction is of very unfavourable omen. A widely distributed, almost universal, dysenteric diarrhoea, a daily exposure to infection by enteric bacilli, here are the elements necessary for a severe epidemic of enteric fever. Mark the importance of such a generalisation if true. Diarrhœa and dysentery in themselves proved as a rule fairly amenable to comparatively simple treatment, but in the light of the foregoing remarks the slightest diarrhoea becomes invested with a new importance and officers and men should be warned to apply for immediate treatment at a time when the simplest measures may have the greatest effect. This warning is sufficiently warranted by considera. tion of dysentery on its own merits, but it becomes donbly so if we look upon it as a co-worker for evil with enteric fever.

Precautions taken by the Authorities to Prevent THE SPREAD OF INFECTION.

At Modder river some of the regiments-the Guards for instance-made efforts in the direction of purifying the water. One tried boiling and clarifying with a small quantity of alum. Another used filters (Berkefeld), having as many as seven large ones going all day, but the water was so thick that the cylinders became clogged every 10 minutes by a thick coat of slime. The Guards' Hospital made use of Pasteur filters. After filtration the water was most palatable. but the objection to the boiling process is that in a tropical climate the water takes so long to cool and when cooled forms a very flat beverage. At any rate, the men preferred the river water in its natural state, and unless sentries were posted along the banks of the two rivers it is difficult to see how they could be prevented from drinking from them even if it were positively known that the water was polluted. Five or six wells were sunk along the bank of the Modder river, but they did not seem to come into general use. The latrines were of the open trench variety, carefully inspected daily, and with sentries over them to see that they were used properly. They were continually being filled in and fresh ones dug. The water-supply at Bloemfontein bas already been discussed and the important measure of substituting the bucket for the open trench latrines has been mentioned. In our hospital and No. 3 General Hospital at the base, it was the custom to disinfect enteric ferer and dysenteric stools with mercuric perchloride solution ( 1 in 250), to remove them to a shed set apart for the purpose, and there to mix them with sawdust for burning. At Bloemfontein the stools were buried after disinfection. On the whole it is difficult to see what more could have been done. It is easy to make suggestions, but after all the carrying of them out will ever be subservient to the exigencies of warfare.

Preventive Inoculation.

The conditions of life of an army on active service, even in camp, may well fill the soul of the sanitarian with despair. It is therefore with hope that we turn to the question of the possible artificial immunity by inoculation which has naturally evoked so much interest in this war. The figures that I have to give on this question are small, but they possess the value of personal observation. The Portland
Hospital went out with the usual personnel of a Base hospital for 100 patients as shown in the table.

TABLE I.-Portiand Hospital.

\begin{tabular}{c|c|c|c|c}
\hline & Inoculated. & $\begin{array}{c}\text { Not } \\
\text { inoculated. }\end{array}$ & $\begin{array}{c}\text { Enteric } \\
\text { fever. }\end{array}$ & Died. \\
\hline $\begin{array}{c}\text { Medical staff (five) } \\
\text { Sisters (four) ... ... }\end{array}$ & 4 & 1 & 0 & 0 \\
$\begin{array}{c}\text { Non - commissioned } \\
\text { officers, orderlies, } \\
\text { and servants (32) ... }\end{array}$ & 24 & 4 & 1 & 0 \\
\hline Total strength (41) & 28 & 13 & 10 & 1 \\
\hline
\end{tabular}

Of the non-commissioned officers, orderlies, and servants 24 were inoculated by us on the royage out, and four of the medical staff at the same time. All of these showed the local symptoms at the time-that is, pain, stiffness, and local erythema; 17 also presented well-marked constitutional symptoms, general feeling of illness, fever, and headache. Nine of the orderlies contracted enteric fever. It is significant that two of these had the disease very severely, and one of them died; both of these had refused inoculation. Of the inoculated cases five had the disease lightly and two rather severely. One of the sisters also had the disease rather badly and she had not been inoculated.

Figures relating to patients admitted to the Portland Hospital.-Including the members of our own personnel above mentioned we had under treatment at the Portland Hospital 232 cases of enteric fever, most of which came under our care while the hospital was at Bloemfontein. These were cases under our personal care and do not include among them convalescents who were entered in the admission and discharge book as patients, but who really only occupied beds for a short time until a train conld take them to the base. If these latter were reckoned the percentages would of course be lower. The following table shows the numbers and mortality among inoculated and non-inoculated (the sister is entered as an officer).

TABLE II.-Portland Hospital.

\begin{tabular}{|c|c|c|c|c|}
\hline \multirow[b]{2}{*}{ Fnteric fever. } & \multicolumn{2}{|c|}{ Recovered. } & \multicolumn{2}{|c|}{ Died. } \\
\hline & Inoculated. & $\begin{array}{c}\text { Not inocu- } \\
\text { lated. }\end{array}$ & Inoculated. & $\begin{array}{c}\text { Not inocu- } \\
\text { lated. }\end{array}$ \\
\hline Officers $(34) \quad \ldots \quad \ldots$ & 21 & 12 & 0 & $1=7 \cdot 6 \%$ \\
\hline 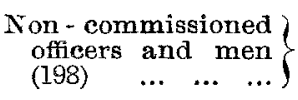 & 29 & 141 & $4=12 \cdot 1 \%$ & $24=146 \%$ \\
\hline Total (232) $\quad \ldots$ & 50 & 153 & $4=74 \%$ & $25=14 \cdot 0 \%$ \\
\hline
\end{tabular}

Of the total number 54 had been inoculated at home or on the voyage out. Of these four died, making a percentage of deaths among the inoculated of only 7.4 per cent. $178 \mathrm{had}$ not been inoculated, and of these 25 died, a mortality of those not inoculated of 14 per cent. The general mortality from enteric fever with us was 29 deaths out of 232 cases, that is 12.5 per cent.

If we take the experience among the officers alone, the evidence in favour of inoculation is still more striking. The officers as a body have presented themselves for iroculation in much larger numbers relatively than the men. This idea is expressed in our figures, but of conrse they must be taken as suggestions only. Of 198 non-commissioned officers and men 33 only had been inoculatedthat is, 16.2 per cent. ; but of 34 officers (including the sister) 21 had been inoculated, or 61.7 per cent.; only one died, and he had not been inoculated. It is scarcely surprising, in view of these figures, that my colleagues and I feel favourably disposed towards inoculation. I saw myself many bad cases among officers and men, not in our own hospital, and 1 am aware that several have died who had been inoculated, but this does not alter the strong general impression, gained by clinical observation, that the disease takes a milder and more benignant course in the inoculated than it does in the non-inoculated. 
General remarks on inoculation.-A few remarks on the general question of inoculation may not be out of place bere. The material used is a sterilised pure culture of enteric fever bacilli in broth. The broth contains, therefore, dead bacilli and a toxin, which toxin, ho vever, seems to be inseparable from the bodies of the dead bacilli, for a filtered broth possessed little toxic power. The supply we took out was given to us by Professor Wright and was prepared in his laboratory at Netley Hospital. The dose is regulated by the quantity necessary to kill a guinea-pig of a certain body-weight. This is generally about 10 centigrammes or from 15 to 18 minims. It is therefore a virulent poison. Injected in the body more or less severe local and constitutional symptoms ensue. The local symptoms consist of pain at the seat of puncture (most often the loin), erythema, and lymphangitis spreading from the wound. The constitutional symptoms may include rigors, fever, headache, a feeling of more or less severe illness, and often a tendency to fain t, all lasting for from 12 to 24 hours. These symptoms vary very much in different individuals. In some there is merely a transient indisposition and a pain in the side; in others there may be bigh fever, a temperature of $103^{\circ} \mathrm{F}$. or more, and all the appearance and sensation of serious illness. After inoculation, for an indefinite period, the blood may give the Widal serum reaction; in my own case it was present three months after, well marked, and was made out faintly 13 months after. The inoculated person is now supposed to be in a state comparable to that of one who has lately had enteric fever; that is, he has had artificially tbrown into his circulation the same toxin which is produced in enteric fever and which possibly influences the activity and growth of the bacilli. He is also assumed to possess, as a result, a certain degree of immunity such as is believed to be acquired by the individual after an attack of the disease. The liability to infection by enteric fever is so variable that we are justified in supposing the existence of an equally varying degree of natural immunity in different persons. Moreover, the toxic saturation point, so to speak, is also a variable one, as is exemplified by the tendency to re-infection or relapse so often seen clinically. I am inclined to think that when the reaction to inoculation is slight it is probably because the person possesses a certain degree of natural immunity, while, on the other hand, a severe reaction indicates proportionate vulnerability to infection. In the former case if the inoculated person take the disease he has it lightly, but in the latter severely. If this be true the toxin reaction possesses a real value as a means of forecast. But again, if this reaction is any measure of the degree of immunity possessed by the individual, it is obvious that after a pronounced reaction one or more re-inoculations should be insisted upon. For all that is claimed for the process is a temporary immunity, and that often partial only. An attack of enteric fever itself does not do much more, for second attacks are far from uncommon.

Inoculation has not yet had a fair trial. Medical officers have been too uncertain as to its value to insist upon on injection even, let alone re-inoculations. It is to be hoped that the figures of the whole army, yet to be published, will indicate with some certainty its value in the direction of lowering the mortality, as those quoted in this paper appear to do; this will justify the medical profession in taking a more decided attitude on the question than it has at present been able to take.

\section{REMARKS ON TREATMENT.}

It may seem almost an impertinence on my part in this presence to make suggestions on treatment, but my doing so may serve as a protest against the attitude in the present day of some of the profession as well as the public in assuming that the care of enteric fever devolves upon the nurse rather than the physician. I have no hesitation in saying that in a disease in which danger threatens from so many points watchful supervision by the physician and prompt treatment of symptoms are not only productive of comfort to the patient, but are also contributory in a high degree to a successful issue. I am of opinion that there may be many worse places in which to undertake the treatment of enteric fever than a comfortable tent in the open air : in fact, there can be no donbt that a tent is superior to a great many buildings, and this should be borne in mind in view of newspaper criticisms on the failure by the medical authorities to secure all the available buildings in Bloemfontein.

Diet.-One of our earliest difficulties at Bloemfontein was the scarcity of fresh milk. It becomes necessary in such circumstances to fall back upon preserved or condensed milk. There are one or two forms of sterilised milk which are as good and palatable as the fresh article, but they are expensive. The condensed milks of numerous brands are excellent for ordinary use, but it is doubtful whether they possess much nourishing power in illness. The common sweetened form is most unsuitable; patients had as a rule an intense objection to it and it caused undoubtedly in some cases tronblesome vomiting. The other forms of nourishment-e.g., arrow-root, beef-tea, \&c.- -we had in plenty. Our principle in dieting was to use all forms of nourishment liberally when, in our opinion, it could be safely done. Most of our patients were thin and ill-nourished before contracting the disease.

For myself I have for many years held the opinion that food may be used much more boldly in enteric fever than is the usual practice. The safety of its employment depends solely on the digestive power of the stomach. If that power is normal, as in many cases it is, meat, for instance, is not likely to reach the ulcerated small intestine in a form more dangerous than a glass of milk is. For milk naturally becomes a mass of curds in the stomach before peptic digestion takes place, and if this latter process is incomplete the undigested curds may be a real source of danger. It seems to me that one should be guided in this matter by the state of the tongue, the evacuations, and the appetite of the patient. If the tongue is moist and fairly clean, if there is no diarrhoea-that is, if the evacuations are no more in number than, say, two a day and fairly consistent-and if there be no tympanites, and the patient has a strong craving for food, it is probable that his digestion will be good and that a liberal diet, including, for instance, finely minced meat, and even thin bread-and-butter, will not only be safe but beneficial. On the other hand, the dry brown tongue, frequent curdy stools, and especially if thele be tympanites and a disinclination for food, indicate a condition of stomach that makes careful dieting imperative. Frequent small feeds of milk, peptonised or diluted with barley-water, Benger's food, \&c., must be used with care and the stools frequently inspected as a guide to the state in which the food reaches the intestines.

But the mechanical effects of undigested food in the small intestines are not the only ones to be feared. Experiment seems to show that the growth of the enteric fever bacilli is favourea and their virulence enhanced by the presence in the intestines of other bacteria, such as are encouraged by the presence of undigested food, and themselves tending to produce gastro-enteric trouble. So that a slight gastroenteritis may have a grave effect on the course of the attack. This has been justly emphasised by Dr. Horton-Smith in his Goulstonian Lectures (1900).

Alcohol we used most sparingly and only in the severer cases in which we feared heart failure, not at all in the milder cases. The small rapid pulse we considered the best indication for its use, not high temperature. We rarely gave more than three or four ounces and never more than six ounces in the 24 hours. The long-enforced abstinence of the soldier from all forms of stimulant renders him rather susceptible to its influence as a drug.

Digitalis and strychnine were of the greatest value. In one or two cases gradually increasing doses of the officinal liquor strychninæ were injected hypodermically to the extent of 30 minims in the 24 hours.

Headache. - This was one of the first symptoms that called for treatment, and from five to 10 grains of phenacetin generally gave speedy relief, or, failing this, a somewhat larger dose of antipyrin. In not a few cases this caused during the sleep that followed a profuse perspiration with perhaps a slight fall in the temperature. Beyond the discomfort of this no ill result followed. In some cases, however, this sweating was so annoying that it became necessary to add from one-hundredth to one-fiftieth of a grain of atropin, which usually stopped it.

Insomnia.-One of the most troublesome symptoms was insomnia and the cry for hypnotics was a very common one. As a rule, all that was necessary was a small dose of phenacetin, which proved as useful for this purpose as it did for headache. To patients who were delirious and constantly attempting to get out of bed we did not hesitate to give hypodermic injections of morphine and in considerable doses, such as a quarter of a grain, repeated several times if necessary.

Mouth and tongue.-The care of the mouth and tongue I 2 
may appear a minor detail. It is not so in the estimation of the patient, and in the severer cases the dry, black, and cracked tongue and lips are more than a discomfort-the pain of taking food may positively prejudice the nutrition of the patient. Local treatment may be all that is necessarymechanical cleansing or the use of mouth-washes, and of these we found one containing potassium chlorate, glycerine, and iron perchloride the most useful. A mixture containing potassium chlorate and sodium bicarbonate given three times a day had a remarkable effect in cleaning and moistening the mouth and tongue, so much so that its use became almost a matter of routine.

Intestinal symptoms.-Diarrhoea is, I believe, less a symptom than a complication and as such requires treatment. In the minds of some it is regarded as an effort of nature to remove deleterious matter. I cannot accept this view, for in all epidemics a considerable, if not a large, percentage of cases have no diarrhcea, and these are, as a rule, favourable cases, whilst among the worst cases diarrhoea is most common. This is shown by the fact that in our 29 fatal cases 21 of the patients had more or less severe diarrhœa. Diarrhoa may be due to general enteritis consequent on extension of inflammation from the ulcerated patches to the general mucous surface of the intestine, but it is probably more often caused by an ulceration of the large intestine. There is no doubt that such ulceration is often found post mortem in the colon, very commonly in the region of the cæcum, and in two or three of our necropsies there was found extensive discrete ulceration of the large intestine even to the rectum. The treatment of this diarrboa was comparatively simple and undoubtedly of great benefit to the patient. Bismuth carbonate or salicylate and chlorodyne proved the most useful drugs, supplemented if necessary by suppositories of one quarter of a grain of morphine. In obstinate cases enemas of 10 per cent. boric acid solution often gave permanent relief, a further hint that the cause of this symptom was in the large intestine. Tympanites, always a dangerons condition, rarely gave us any trouble ; it is best treated by boric injection. A small injection of about four ounces of water containing two grains of quinine and half an ounce of brandy would often cause the patient to pass flatus with great relief. Hæmorrhage occurred in 10 cases, on the average at about the eighteenth day. In some it was very severe and was repeated two or three times and was so profuse as to canse blanching. It was almost invariably accompanied by a sudden fall of temperature and invariably by a rise in the pulse-rate. In only one was it found after death, not having been suspected during life, with which exception it never proved fatal, and though four of these patients died ultimately no blood was found in the alimentary tract. Hæmorrhage always yielded to, or after, treatment, which consisted of a mixture containing oil of turpentine and tincture of hamamelis of each half a drachm, and tincture of digitalis three minims. This was given every two hours, or alternately every hour with a drachm of hazeline. One of us used hazeline alone-a drachm every hour-with apparently equally good results. At the same time morphine suppositories were administered. Under this treatment the stools rapidly ceased to contain bright blood, and in about 12 hours were free from blood altogether. Perforation occurred in five of our patients, averaging at ab ut the thirty-fifth day. The earliest day of occurrence was the nineteenth and the latest the fifty-first day of the disease. The prognosis of this terrible accident is gloomy in the extreme, whether viewed from a medical or a surgical standpoint. There is reason to believe that in a very small percentage of cases the resulting peritonitis may become localised, but this happy event cannot be foreseen because it seems that the symptoms are rarely if ever, proportional to the extent of the peritoneal inflammation. The symptoms of peritonitis in the course of enteric fever are not those of the same accident in a comparatively healthy person. The local pain, for instance, is rarely so severe and may be almost absent, so also is the characteristic position of body. Abdominal movement may be present and ample. The absence of liver dulness as a sign is frequently wanting. But a rise in the pulse and respiration rates and a sudden fluctuation of temperature are almost invariable and of these the former is the most constant. The diagnosis baving been made the physician has two courses of treatment open to him, either equally unsatisfactory. The medical treatment amounts to the securing of absolute rest to the intestines in the hope of plastic localisation of the inflammatory process, and this, of course, is best obtained by the free use of opium. If the issue must be fatal this treatment is humane, if nothing else. The surgical treatment is as unsatisfactory as the medical, but nevertheless it is a question whether it is not the duty of the physician to recommend it. It offers a slender chance of recovery and it is possible that as time goes on this chance may be improved. The history of abdominal surgery warrants this hope. If surgeons had allowed the high mortality in the early days of abdominal operations to deter them from operating repeatedly that method of treatment would never have attained the position it now holds. It is difficult, however, to imagine a more unfavourable case for operation than a person suffering from enteric fever, at any date of the disease. The operation itself offers no peculiar difficulties, but in the two that were attempted by us we were glad to get the patient off the table alive. In neither case was the operation performed until from 10 to 12 hours after the first symptom, and it is, of course, possible that if it had been resorted to earlier the result might have been more favourable. The best one can say is that the patients both expressed themselves as feeling more comfortable and quite free from pain, but nevertheless they died four or five hours afterwards.

Harley-stréet, W.

\section{THE CLINICAL AND PATHOLOGICAL RELATIONS OF THE CHRONIC RHEUMATIC AND RHEUMATOID AFFECTIONS TO ACUTE IN- FECTIVE RHEUMATISM. ${ }^{1}$}

\section{BY AROHIBALD E. GARROD, M.A., M.D. OXON.,} F.R.C P. LOND.

PHYSTCIAN TO THE HOSPITAI FOR STCK CHITDREN, GRHAT ORMONDSTREET ; MEDICAI REGISTRAR AND DEMONSTRATOR OF MORBID ANATOMY AT ST. BARTHOLOMEW'S HOSPITAL.

A GLANCE through the table of contents of any modern text-book of medicine suffices to bring home to one the fact that in the matter of the classification of diseases we are living in a period of transition, a period of compromise. The primitive but natural plan of grouping morbid conditions according to the organs or structures specially implicated is still largely adhered to. On the other hand, we find evidences of the dawn of a more scientific system of classification, and we may reasonably expect that before very many years shall have passed away our knowledge will have so far advanced that it will be possible for works to be written in which the various manifestations of each separate morbid process will be so brought together as to form parts of a continuous and comprehensive description. Although this is even now possible to a limited extent it is clear that extensive gaps in our knowledge will have to be filled up before large portions of the field of medicine can be so treated and for the present the timehonoured plan must in many instances be adhered to.

By no department of medicine is this process of transition from one system of classification to another better illustrated than by that which we are this evening met together to discuss. Out of a primitive category of "arthritis" various distinct forms of articular disease have been successively differentiated. The first such sub-division occurred as long ago as the seventeenth century, when Baillou first called attention to the special features of acute rheumatism and drew a distinction between that disease and gout. The next advance did not come until the meeting of the eighteenth and nineteenth centuries, when the further differentiation was made of the conditions now known as rheumatoid or osteo-arthritis from rheumatism by Haygarth and Heberden in our own country and from gout by Landré Beauvais in France. Since then the advance has been more rapid and not a few special forms of articular lesions have been distinguished, such as gonorrhoeal arthritis, the arthritides of certain specific fevers, the arthropathies met with in tabes dorsalis and other nervous affections, and the peculiar joint affection to which

1 The opening paper in the annual clinical debate at the Chelsea Clinical Society on March 12th, 1901 